\title{
ESTABELECENDO CONFLUÊNCIAS: SUSTENTABILI- DADE E A ÉTICA DA ALTERIDADE DE EMMANUEL LÉVINAS
}

\section{ESTABLISHING CONFLUENCES: SUSTAINABILITY AND THE ETHICS OF ALTERITY OFEMMANUEL LEVINAS}

Paola Zambon Azevedo, M.Sc. (UNIRITTTER)

Carla Pantoja Giuliano, Dra. (UNIRITTTER)

Ricardo Libel Waldman, Dr. (UNIRITTTER)

Anne Anicet Ruthschilling, Dra. (UNIRITTTER)

\section{Palavras Chave}

Alteridade; Ética; Sustentabilidade

\section{Key Words}

Alterity; Ethics; Sustainability

\section{RESUMO}

O presente artigo estabelece possíveis relações entre a Ética da Alteridade, assunto de relevante destaque na filosofia de Emmanuel Lévinas, com a Sustentabilidade e suas principais questões. Como estrutura, o artigo versa inicialmente sobre os conceitos de Ética, de Alteridade, e posteriormente, da Ética da Alteridade, sob a visão do filósofo Emmanuel Lévinas. Em um segundo momento, aborda-se questões em evidência nas atuais discussões sobre Sustentabilidade e Desenvolvimento Sustentável. Por fim, dialoga-se acerca dos temas centrais deste artigo, em Relações entre a Ética da Alteridade e a Sustentabilidade. O intuito primordial do artigo é suscitar reflexões acerca da contemporaneidade, da insustentabilidade, do comportamento padrão vigente da sociedade e do seu afastamento dos valores éticos e alteritários.

\section{ABSTRACT}

This article establishes the possible relationships among Ethics of Alterity, a relevant matter in the philosophy of Emmanuel Lévinas, with sustainability and its primary issues. As structure, this article firstly addresses about the concepts of Ethics, Alterity, following the Ethics of Alterity under the vision of the philosopher Emmanuel Lévinas. In a second moment, featured issues are addressed among the prevailing discussions about Sustainability and Sustainable Development. Lastly, the main themes in this article are discussed in Relations among the Ethics of Alterity and Sustainability. The main goal of this article is to incite reflections about the contemporaneity, the unsustainability, the current standard behavior of society and its deviation from the Ethical and Alterity values. 


\section{INTRODUÇÃO}

Não é preciso que sejamos biólogos para perceber a grande deterioração que o homem vem causando ao ambiente natural ao longo de sua história. Hoje, em qualquer lugar, a qualquer instante, qualquer pessoa sabe, ou sente, que o planeta Terra vive um período de intensas transformações técnico-científicas, em contrapartida das quais engendram-se fenômenos de desequilíbrios ecológicos, que, se não forem remediados, no limite, ameaçam a vida em sua superfície. (PINTO, 2007).

Manzini (2008) relaciona a deterioração ambiental vivida atualmente, não apenas com os problemas ambientais enquanto natureza, mas também com a saturação do mercado, o desemprego, a proliferação de guerras regionais para o controle dos recursos naturais, a emigração e consequentes problemas raciais, e por fim, a dificuldade de se imaginar o futuro, devido à consciência limitada do homem, que o permite ver o futuro somente como a continuação do passado, baseado em um crescente consumo material.

A humanidade vive hoje diante de um futuro incerto. A modernidade, apesar de todas as conquistas da ciência e da tecnologia, acaba por encaminhar a sociedade para a exploração e divisão, ao invés de emancipar e libertar o homem. O desejo de emancipação, proveniente do uso da razão e dos recursos por ela proporcionados, acabou assumindo um rumo indesejado, e como consequência, o homem vive hoje um momento de ruptura dos padrões e dos modelos fundamentadores, ou seja, de paradigma civilizatório geral (PINTO, 2007).

Atualmente, a força motivadora para a transformação está no fato de que os limites do planeta tornaram-se evidentes, e a partir dessas percepções, o homem deve olhar não apenas para o que é denominado como "problemas ambientais" (MANZINI, 2008). Schulte e Rosa (2010) afirmam que o grande desafio da humanidade no século XXI é a sustentabilidade ambiental, mantendo o bem-estar atual, sem comprometer o bem-estar das futuras gerações.

Talvez seja no momento presente, mais do que em qualquer outro período da humanidade, que o ser humano precise buscar, no escuro, o reencontro consigo mesmo e com a natureza, procurando a luz que lhe indicará um novo caminho, uma nova forma de se relacionar com o seu ambiente e com si mesmo. Para tanto, é necessário uma reconsideração de valores fundamentais para a formulação de novos padrões de comportamento e da sociedade como um todo (PINTO, 2007).
Dentre os valores necessários, a Alteridade e sua Ética tornam-se fundamentais para iluminar o homem, como elemento basilar da construção de uma nova cultura que impulsione cada indivíduo a reencontrar-se consigo mesmo e com a natureza, reestabelecendo a paz, o respeito e o equilíbrio com o meio que o cerca. A Ética da Alteridade, que é a visão, a inclusão e o respeito ao Outro, é neste momento, a pedra angular da construção de um novo futuro.

O presente artigo versa inicialmente sobre os conceitos primordiais de Ética, de Alteridade, e posteriormente, da Ética da Alteridade, sob a visão do filósofo Emmanuel Lévinas. Em um segundo momento, aborda-se questões em evidência nas atuais discussões sobre Sustentabilidade e Desenvolvimento Sustentável. Por fim, dialoga-se acerca dos temas centrais deste artigo, em Relações entre a Ética da Alteridade e a Sustentabilidade, que se divide em três momentos, e tratam de assuntos fundamentais tanto nos estudos sobre Sustentabilidade, como na obra de Lévinas, sendo eles: Futuro do Planeta, Responsabilidade e Consciência.

\section{2. ÉTICA E ALTERIDADE}

\section{1. Ética}

Descrevo a ética, é o humano, enquanto humano. [...] O único valor absoluto é a possibilidade humana de dar, em relação a si, prioridade ao outro. Não creio que haja uma humanidade que possa recusar esse ideal, mesmo que se deva declará-lo ideal de santidade. Não digo que o homem é um santo, digo que é aquele que compreendeu que a santidade era incontestável. É o começo da filosofia, é o racional, é o inteligível. (LÉVINAS, 2009, p. 149-150).

Lévinas compreende a ética como interpelação justificante, como linguagem que transita na interpelação voltada para o outro (SOLDERA et al., 2006). Conforme Pinto (2007), a ética pode ser definida como o campo do conhecimento que envolve todas as relações humanas, com todo seu contexto, seu universo.

A construção ética está embasada na pressuposição de que a ética surge quando o Outro emerge diante de nós. O Outro pode ser qualquer pessoa, classe social ou em perspectiva mais global, a natureza, o planeta. Diante do outro não há como se manter indiferente. Mesmo optando pela indiferença ao outro, já se considera aí uma tomada de posição, considerado também como um comportamento ético, já que a ética surge a partir do modo 
como se estabelece a relação com o outro. O indivíduo ético pode fechar-se ao outro, negá-lo, dominá-lo, submetê-lo ou destruí-lo (PINTO, 2007).

Para Lévinas, a verdadeira relação ética nasce da relação "face a face", interpessoal, onde não se trata de pensar conjuntamente o "Eu e o Outro", mas sim de estar diante do Outro, da sua face, frente a frente. A partir da relação "face a face" cria-se uma relação de responsabilidade, pois no momento em que estou de frente para o Outro, sou responsável por ele (SOLDERA et al., 2006).

Lévinas, ao referir-se à relação de responsabilidade pelo Outrem, o estar "frente a frente", que é dado pelo fundamento do reunir-se em sociedade, estabelece o conceito de "rosto". "Nesse sentido, o autor nos diz que esse "estar frente a frente ou face a face", é um acesso ao rosto, que em um primeiro momento, é ético. A partir daí, acabo me tornando responsável pelo Outro." (SOLDERA et al., 2006, p. 2).

Consoante Soldera et al. (2006), o que Lévinas buscou em seus escritos foi uma ética fundamental, pois a linguagem aparente na relação de estar "face a face" é um chamado a bondade e a justiça. Emmanuel Lévinas, em sua obra intitulada "Entre Nós" (2009), cita Descartes quando fala de generosidade, relacionando seu conceito à relação ética, já que o filósofo afirma que não estima nada mais importante do que fazer o bem aos outros homens, desprezando assim o seu próprio interesse para tal fim.

Como último conceito da Ética em Lévinas, é relevante ressaltar que para o autor em questão, a ética é considerada como filosofia primeira:

\footnotetext{
A ética é a filosofia primeira, anterior a toda filosofia possível. É anterior a aventura do saber e às truculências da tematização. [...] Assim como a sensibilidade e o recebimento são anteriores a razão temática e à estratégia arrazoada, assim também a ética é anterior a fenomenologia transcendental, à ontologia fundamental existencial e a toda filosofia possível. (COSTA, 2000, p. 29).
}

Soldera et al. (2006) afirma que, para Lévinas, a ética é filosofia primeira e desde o início orientada para o Outro que é absolutamente Alteridade. Tratando da ética como filosofia primeira, determina que o encontro, o estar "face a face", aconteça com respeito à Alteridade do Outro, pois o existir requer que o Outro mantenha-se si mesmo, identidade de si mesmo.

\subsection{Alteridade}

A palavra Alteridade tem origem no latim "alter", significando "outro", e é conceituada principalmente, de maneira universal e afirmativa, a partir da filosofia de Emmanuel Lévinas (SIDEKUN, 2006).

Alteridade significa colocar-se no lugar de Outrem, na relação interpessoal, com valorização, consideração, identificação e diálogo com o Outro (PINTO, 2007). Segundo Soldera et al. (2006), a relação proposta por Lévinas para alcançar a Alteridade está na exterioridade, sendo não uma preocupação para comigo, mas sim para com o Outro.

A prática da Alteridade se dá não somente entre indivíduos, como também entre grupos ou ainda entre o indivíduo e a natureza. A vivência da Alteridade compreende os fenômenos da complementaridade e da interdependência, no modo de pensar, de sentir, de agir, sem a preocupação com a sobreposição ou destruição do Outro com o qual nos relacionamos (PINTO, 2007).

De acordo com Pinto (2007), a Alteridade conduz as relações interpessoais da diferença à soma, na medida em que propõe o estabelecimento de uma relação pacífica e construtiva com os diferentes, passando o indivíduo a se identificar, compreender e aprender com o contrário, com o Outro.

Compreender uma pessoa é já falar-lhe. Pôr a existência de outrem, deixando-a ser, é já ter aceito essa existência, tê-la tomado em consideração. "Ter aceito", "ter considerado", não corresponde a uma compreensão, a um deixar-ser. A palavra delineia uma relação original. Trata-se de perceber a função da linguagem não como subordinada a consciência que se toma da presença de outrem ou de sua vizinhança ou da comunidade com ele, mas como condição desta "tomada de consciência". (LÉVINAS, 2009, p. 27).

Lévinas (2009) traz como questão fundamental para a Alteridade, assim como o fez na Ética, o estabelecimento da responsabilidade de um indivíduo para com o Outro. De acordo com o autor, o encontro com Outrem é imediatamente minha responsabilidade por ele. Aqui é discutida novamente a questão do "rosto", onde ressalta que é a partir da responsabilidade com o Outro, do encontro com o "rosto", que a justiça aparece, que comporta julgamento e comparação, comparação daquilo que, em princípio, é incomparável, pois cada ser é único, ou seja, todo Outrem é único. Segundo Lévinas (2009), é a partir do encontro 
com a justiça que se manifesta a ideia de equidade, permitindo assim, que o indivíduo caminhe rumo à sabedoria da caridade, à sabedoria do amor para com o Outro.

\subsection{A Ética da Alteridade}

A partir do encontro da Ética com a Alteridade, dá-se o fundamento da Ética da Alteridade. Para Soldera et al. (2006), a fundamentação ética a partir da Alteridade relaciona-se em primeiro lugar com a valorização do humano, a partir do reconhecimento do Outro.

Pinto (2007) define que a Ética da Alteridade é a capacidade de conviver com o diferente, indivíduo, grupo ou natureza, através de um olhar voltado justamente para o reconhecimento e o acolhimento das diferenças. Significa reconhecer o outro em si mesmo, com os mesmos direitos, deveres e responsabilidades. Bernardes (2012) complementa ao afirmar que a Ética da Alteridade garante ao homem a compreensão do Outro enquanto ser constituído de dignidade.

O estabelecimento da Ética da Alteridade leva o indivíduo a um comportamento de justiça, humildade, acoIhimento e interpelação para com o Outro. O encontro da ética com a Alteridade embasa-se na manifestação de ações que não visam subtrair nada do Outro, mas sim, edificar nas pessoas uma intenção de agir de forma justa, já que o maior objetivo da ética é o bem que inclui a todos (SOLDERA et al., 2006).

Consoante Melo (2003), Lévinas define que a ética, enquanto relação com a Alteridade, encontra-se no mesmo plano da religião, ou ainda, a ética da alteridade é a religião do outro:

[...] o outro, aquele que me transcende e que me revela o mistério mais profundo da criação: o outro, enquanto pessoa, é terra santa, é sacralidade e, para aproximar-se dele, é necessário tirar as sandálias, despojar-se de si mesmo, escutá-lo, olhá-lo, senti-lo próximo. (MELO, 2003, p. 270).

A filosofia de Lévinas é constituída nos horizontes da responsabilidade, em que sua ética prima pelo movimento de acolhida e não de tentativa de posse, domínio ou eliminação da Alteridade. E esta, por sua vez, possui o papel de assinar e garantir o cumprimento da proposta ética levinasiana. Considerada como princípio fundamental, a responsabilidade aliada à Alteridade, leva o Outro ao centro, porém no sentido relacional, e não como referência última. Desta forma, a relação ética torna-se a religião do Outro, fundada na responsabilidade originária do Mesmo pelo Outro. A ética aguarda uma resposta do homem, assim como Deus espera uma resposta do homem: o amor dele pelo seu próximo. "Nesse modo de amar, encontra-se a via que conduz o homem para a eternidade. $O$ amor do homem pelo seu próximo é uma tarefa que o redime, é o efeito da sua própria redenção." (SOLDERA et al., 2006, p. 5).

O conceito de "Rosto" complementa a ética fundamentada na Alteridade através de ações como o respeito, que instaura no indivíduo não apenas a percepção do que se vê, o "rosto", a parte do Outro, mas sim uma proposição de entendimento do que isso significa. Para tanto, é necessário perceber, ver e sentir o "rosto" do Outro com um novo olhar, não somente no sentido de comiseração ou empirismo, mas principalmente com um olhar fundamentado na justiça (SOLDERA et al., 2006).

Pelizzoli (2002) expõe que o trabalho filosófico de Emmanuel Lévinas posta-se em essência como denúncia da violência contra o humano. $\mathrm{O}$ autor afirma que neste "humanismo do outro homem", a exigência ética é proposta como o sentido profundo do homem, que o eleva ao humano como realização tanto individual como social.

É na ética fundamentada na Alteridade, principalmente embasada pelo ato de ser responsável pelo Outro, a busca por equidade e justiça, e reconhecimento dos direitos do Outro, que este ensaio busca a aproximação com a temática da Sustentabilidade, como um estabelecimento de consciência e responsabilidade perante o Outro, sendo este um indivíduo, um grupo, a sociedade como um todo, ou de forma mais ampla, o meio em que esse indivíduo habita: o planeta.

\section{SUSTENTABILIDADE E DESENVOL- VIMENTO SUSTENTÁVEL}

Há cinquenta anos atrás em nosso planeta viviam três bilhões de pessoas. Hoje chegamos a seis bilhões. Em 2050 teremos dezenas de bilhões. Estima-se que os recursos não serão suficientes para todos. Serão necessários água, alimentos, energia e matérias-primas para o homem, originando novas guerras. $O$ desmatamento, as emissões não controladas de dióxido de carbono e metano, as secas e as inundações causadas pelo aquecimento global, o consumismo desenfreado e o desperdício vão acelerar o esgotamento dos recursos disponíveis até o ponto de não haver retorno. A redução de peixes pode significar que até 2050 não haverá mais peixe para pescar. Já estamos em plena crise mundial de alimentos: um bilhão de pessoas passando fome. No 
mundo inteiro, só no ano passado, uma em cada 50 pessoas perderam suas casas devido à guerra, terremoto, inundação, incêndio, ou danos do aquecimento global. Enquanto se buscam soluções para combater o aquecimento global, surge o espectro ameaçador de cenários apocalípticos de prospecção da energia nuclear. (BROWN, 2010, p. 7, tradução nossa).

O panorama descrito por Brown (2010) revela o atual momento em que o homem vive, frente as suas ações para com o meio ambiente. Berlim (2012),sugere que grande parte do atual desregramento da natureza, deve-se ao desenvolvimento industrial, nos últimos dois séculos, o que impactou o planeta de forma contundente, causando grandes danos à humanidade. A autora cita como principais prejuízos a degradação do ambiente natural, a perda de biodiversidade, as mudanças climáticas, o aumento do efeito estufa, a chuva ácida, a deterioração dos solos, o desperdício e uso leviano dos recursos naturais, o crescimento excessivo do lixo e, em especial, a fome e a miséria.

A crise ecológica atual é um tema extenso e amplamente debatido, porém, ainda para muitos políticos, assim como para a humanidade como um todo, é um tema que gera incômodo (EDWARDS, 2008). Para tanto, devido a crescente preocupação e aumento da insustentabilidade, torna-se imperativo uma mudança a nível global, onde cabe destacar os esforços para se propagar o conceito e as atitudes que englobam a Sustentabilidade.

Vezzoli e Manzini (2007) definem o termo Sustentabilidade como referente às condições sistêmicas que, a nível global e regional, as atividades humanas não podem perturbar os ciclos naturais, que são baseados em mais do que a resiliência do planeta permite e, ao mesmo tempo, não esgotar o capital natural, que será transmitido às gerações futuras. Os autores ainda acrescentam um terceiro requisito, de caráter ético, à definição do termo Sustentabilidade: o princípio da equidade, onde afirmam que qualquer pessoa, incluindo as futuras gerações, possui o direito ao mesmo espaço ambiental, ou seja, a mesma disponibilidade aos recursos naturais e globais.

Sustentabilidade é a preservação da vida através do equilíbrio ecológico - humano, animal, vegetal e planetário. Um sistema autossuficiente é um sistema que não toma do meio ambiente mais do que ele pode devolver, que não exaure seus recursos e que se autossustenta. (BROWN, 2010, p. 9, tradução nossa).
Para Berlim (2012) a Sustentabilidade está baseada em oito critérios: o social, o cultural, o ecológico, o ambiental, o territorial, o econômico, o político nacional e o político internacional, demonstrando que a Sustentabilidade engloba todas essas áreas de forma interdisciplinar.

Considerando a crise ambiental e a definição de Sustentabilidade, é nítido o quanto o sistema de produção e consumo das sociedades industriais contemporâneas estão distantes do que se espera de um comportamento sustentável (VEZZOLI; MANZINI, 2007).

No período dos anos 1960, a crise ambiental começou a ser analisada e debatida por pesquisadores e ambientalistas. A percepção de uma série de desastres e desequilíbrios do ecossistema levou a comunidade científica e os governantes conscientes, a considerarem essa questão como um problema de ordem mundial. Essa preocupação gerou a primeira conferência global voltada para a questão ambiental, a Conferência das Nações Unidas para o Meio Ambiente Humano, em Estocolmo, na Suécia, ocorrida no ano de 1972 (BERLIM, 2012).

Anos após a Conferência de Estocolmo, já em 1987, a Assembleia Geral da Organização das Nações Unidas (ONU) criou a Comissão Mundial sobre o Meio Ambiente e Desenvolvimento, presidida pela então primeira-ministra da Noruega, Gro Harlem Brundtland (BERLIM, 2012). Neste encontro, a expressão "desenvolvimento sustentável" foi introduzida no debate internacional pela primeira vez em um documento chamado "Nosso Futuro Comum" (Our Common Future), conhecido também como Relatório Brundtland (MANZINI, 2008).

A Comissão Brundtland definiu o desenvolvimento sustentável como aquele que "satisfaz as necessidades do presente, sem comprometer a capacidade das futuras gerações de satisfazer suas próprias necessidades." (EDWARDS, 2008, p. 20). Para o autor, essa definição talvez seja o maior imperativo para o desenvolvimento global no século XXI.

Vezzoli e Manzini (2007) consideram que a definição do Relatório Brundtland não fala do meio ambiente enquanto tal, mas refere-se ao bem-estar das pessoas como uma expressão da qualidade ambiental. "Nosso Futuro Comum" introduziu um princípio ético fundamental: a responsabilidade da atual geração contra as gerações de amanhã.

De acordo com Berlim (2012), os principais pontos apresentados no documento "Nosso Futuro Comum" foram: a incompatibilidade entre os padrões de produção industrial e consumo da época e a possibilidade de um futuro digno para as gerações futuras; e um novo olhar sobre o conceito de desenvolvimento. Para a autora, o 
Relatório se baseia em três pilares de igual valor, sendo eles a justiça social, a viabilidade econômica e a preservação ambiental.

A partir de então, a expressão "desenvolvimento sustentável" foi cada vez mais usada, até tornar-se o tema central de debate na Conferência das Nações Unidas sobre o Ambiente e Desenvolvimento, realizada em 1992 no Rio de Janeiro (MANZINI, 2008). Dez anos mais tarde o tema também foi destaque na Cúpula Mundial sobre Desenvolvimento Sustentável, em Johannesburgo (VEZZOLI; MANZINI, 2007).

A introdução do termo "desenvolvimento sustentável" revelou que a promessa de um bem-estar baseado na continuidade do modelo de desenvolvimento dos países ricos (chamados "desenvolvidos") e na incentivação do estabelecimento deste modelo aos países "subdesenvolvidos" ou "em desenvolvimento", não poderia mais ser mantida, devido ao seu funcionamento estimular o rápido consumo do capital natural e extrapolar a capacidade de recuperação dos ecossistemas. (MANZINI, 2008).

Berlim (2012) explana que no ocidente estabeleceu-se uma lógica evolucionista de que a melhoria da sociedade está associada à lógica do crescimento econômico e do seu progresso, e que esta ideia tornou-se a base da compreensão do que é chamado "desenvolvimento". Consoante a autora, compreender e transformar a lógica do desenvolvimento e do progresso está entre os maiores desafios para as futuras gerações.

\section{RELAÇÕES ENTRE A ÉTICA DA ALTERIDADE E A SUSTENTABILIDADE}

\subsection{O Futuro do Planeta}

A humanidade atual passa por um poderoso momento de incitação à mudança, frente ao fato de que os limites do planeta, ou seja, os problemas ambientais tornaram-se evidentes (MANZINI, 2008). Conforme Pinto (2007) a perda da Alteridade, da visão do Outro e do meio ambiente como Outro, transformou o homem no grande ocasionador do desequilíbrio ecológico, assim como da violência, da intolerância e do separatismo.

Bernardes (2012) afirma que o comportamento autônomo e antropocêntrico do homem pós-moderno gerou o trágico paradoxo de uma civilização sem ética, baseada no irresistível avanço para a universalização e que, erroneamente, não se fez acompanhar pela formação de uma ética igualmente universal. $\mathrm{O}$ autor complementa que essa mentalidade, oriunda do século $\mathrm{XX}$, apesar de todos os avanços e benefícios que produziu, tornou o homem atual, tido como emancipado e livre, capaz de realizar atrocidades como os totalitarismos, as guerras mundiais e outras barbáries. Bernardes (2012) aponta que é devido ao distanciamento dos valores éticos e morais, que no século atual constata-se o afloramento do homem à solidão existencial, à depressão e às inúmeras patologias mentais.

Vezzoli e Manzini (2007) constatam que a capacidade dos seres humanos em fazer o mal é de natureza inerente à sua maneira de ser, mas que, entretanto, na natureza do homem há também a capacidade de amar, de sentir compaixão, assim como, prosaicamente, de utilizar sua capacidade intelectual para tentar obter o menor dano possível. Segundo os autores, a vida dos indivíduos e dos grupos sociais sempre se desenvolveu a partir do entrelaçamento e da combinação dessas duas distintas capacidades humanas. A partir desta dialética, emerge a questão de como, no futuro, essas capacidades serão combinadas, tendo em vista que a prevalência da primeira sobre a segunda significa o fim da história.

A Ética da Alteridade encontra-se com o pensamento de Vezzoli e Manzini (2007), pois a escolha do homem pós-moderno, de não viver com o Outro, mas apenas justaposto, o tornou oposto a este, transformando-o em malfeitor do Outro. Desta forma, o "rosto" do Outro é marcado pela dor da indignidade, da falta de recursos, da miséria e do preconceito, vítima de um sistema opressor e alienante. "Este panorama clama por uma ética comportamental capaz de (re) valorizar o Outro" (BERNARDES, 2012, p. 90).

$\mathrm{O}$ caminho da mudança rumo à Sustentabilidade, à preservação e à regeneração do capital ambiental e social significará romper com as tendências dominantes em termos de estilo de vida, produção e consumo (MANZINI, 2008). Edwards (2008) defende que somente por meio do uso de tecnologias mais inteligentes, de um maior respeito aos recursos naturais e da substituição de recursos não renováveis por práticas renováveis, será possível minimizar a pressão do homem sobre o meio ambiente.

Manzini (2008) alerta que se as tendências da sociedade não forem alteradas, o homem assistirá a verdadeira conservação, resultante dos atuais e catastróficos estilos de vida, produção e consumo. Futuramente, o sistema de produção e consumo de uma sociedade sustentável será profundamente diferente da conhecida e sustentada na contemporaneidade.

Para que haja a mudança, no caminho do desenvolvimento sustentável, é necessário o esforço de toda a humanidade, das sociedades mais industrializadas àquelas de mais recente industrialização ou ainda não industrializadas, com o objetivo de criarem novas formas de 
desenvolvimento, distantes das conhecidas e dominantes até hoje (MANZINI, 2008).

Sidekun (2006) declara que o pleno reconhecimento da Alteridade do Outro ser humano, dependerá da superação do temor em perder a vantagem compartilhada pelo materialismo ou, em termos de economia, em conservar-se interessadamente em um pragmatismo e utilitarismo ético.

Para o pleno desenvolvimento sustentável, Manzini (2008) afirma que é imperativo uma "descontinuidade sistêmica", onde o homem deve mover-se na direção de uma sociedade capaz de se desenvolver a partir da redução dos níveis de produção e consumo material atuais, resultando assim, em uma melhora na qualidade de todo o ambiente social e físico. Porém, até o momento presente, não foi posto em discussão os atuais paradigmas econômicos e sociais, e consequentemente, as linhas básicas da economia política e social ainda encaminham o sistema vigente na direção oposta à sustentabilidade.

A convivência com a Alteridade implica em repensar os paradigmas vividos pela sociedade em relação à cultura e as suas instituições como a política, a economia, a educação, direito, entre outras. Portanto, uma nova reflexão deve ser disposta, repensando a Ética na Política, no Direito, na Educação etc (SIDEKUN, 2006).

Portanto, a transição rumo à sustentabilidade será um processo de mudanças e aprendizagem social, em que as mais diversificadas formas de criatividade, conhecimento e capacidades organizacionais deverão ser valorizadas de maneira aberta e flexível. As iniciativas locais desempenharão um papel especial, pois serão capazes de romper os padrões consolidados e guiar a sociedade a novos comportamentos e modos de pensar. Esse emergente comportamento de mudança social tem a capacidade de ser um poderoso guia na transição rumo à sustentabilidade (MANZINI, 2008).

\subsection{Responsabilidade}

Como já referenciado, o paradigma do desenvolvimento vem se apresentando como o principal gerador dos graves problemas ambientais, como o aquecimento global, a perda da biodiversidade e de diversidade cultural. Assim como, é agente de disparidades sociais e globais, promovendo a desigualdade racial, de gênero e de acesso a cultura e ao emprego. Kazazian (2005) expõe que tornar esse desenvolvimento responsável é pensá-lo em harmonia com o futuro, é pensar em um desenvolvimento erigido sobre a responsabilidade e a solidariedade do presente para com o planeta e seu futuro.
Para Melo (2003) a responsabilidade é o coração do estatuto da Ética da Alteridade. Conforme Makiuchi (2011) a responsabilidade perante a humanidade e o seu meio se faz cada vez mais necessária, em face aos desafios vivenciados a partir do século $X X$, resultantes do desenvolvimento descontrolado da tecnologia e da ciência e o conflito entre os fins e os meios da globalização. $\mathrm{O}$ autor argumenta que:

\begin{abstract}
Esta responsabilidade é introduzida no âmbito do que é dito no discurso entre o eu e o outro, entre o mesmo e o outro: o outro se refere ao seu mundo, apresenta-o ao mesmo; entretanto, este mundo apresentado não é um mundo solitário, ou melhor, vazio, ele é povoado de objetos, ideias e pessoas, é um mundo vivo que também apela a ele e demanda sua responsabilidade, já que o sujeito ético não pode responder unicamente pelo rosto singular que o solicita, abandonando todos os demais. (MAKIUCHI, 2011, p. 91).
\end{abstract}

Manzini (2008) menciona a expressão "sustentabilidade social" como sendo referente às atividades humanas contradizentes aos princípios de justiça e de responsabilidade em relação ao futuro, considerando a atual distribuição e a futura disponibilidade de espaço ambiental. Este conceito de espaço ambiental relaciona-se com os princípios de justiça e responsabilidade em relação ao futuro. O princípio de justiça, de acordo com a definição acima, declara que cada pessoa possui o direito ao mesmo espaço ambiental. O princípio de responsabilidade em relação ao futuro aponta que é necessário garantir às gerações futuras pelo menos o mesmo espaço ambiental, ou seja, a mesma quantidade e qualidade de recursos ambientais, que atualmente possuímos.

Lévinas (2009) discute a relação entre justiça e responsabilidade. Para ele, a justiça é proveniente do amor, sendo que este último deve sempre vigiar o primeiro. De acordo com Bernardes (2012), o princípio de responsabilidade designado por Lévinas determina que o homem deve ser sempre responsável pelo Outro, sem a espera de reciprocidade, e esta é a condição para a compreensão da possibilidade de justiça na sociedade.

Para Kazazian (2005) o princípio de responsabilidade é um conceito amplo e está ancorado no princípio da precaução, da prudência e do bom senso. O autor esclarece que toda ação é acompanhada de uma série de riscos, e desta forma, a vigilância deve ser constante, pelo motivo de que não se pode garantir a inocuidade de muitas das 
ações humanas, que das mais banais às mais racionais, podem influenciar gravemente o futuro do planeta.

Portanto, de acordo com o conceito de responsabilidade de Lévinas, o homem é responsável por uma total responsabilidade sobre o Outro, que engloba "todos os Outros e por tudo junto a Outros (...) somos todos responsáveis por tudo e por todos, perante todos, e eu mais que os Outros" (BERNARDES, 2012, p. 97). Para Lévinas (2009) esse é o princípio essencial da consciência humana.

Consoante Kazazian (2005) a responsabilidade socioambiental se estende ao indivíduo e aos seus valores éticos e morais. Segundo o autor, a responsabilidade está relacionada a um agir responsável, em que o indivíduo possui plena consciência das consequências de seus atos e é capaz de compreender e considerar, a cada tomada de decisão, a relação de interdependência que existe entre as esferas econômicas e sociais e a biosfera.

Portanto, uma nova forma de agir com responsabilidade pode ser ressonante com a proposta de respeito à Alteridade humana e de tematização de um planeta que, mesmo que sustente, defina biologicamente e fisicamente e contextualize historicamente os homens, é aberto e dinâmico e do qual a humanidade está separada, ainda que faça parte dele. Esta separação invoca a responsabilidade pelo Outro, não só pelo ser humano, como também pelo mundo e por toda sua biodiversidade (MAKIUCHI, 2011).

\subsection{Consciência}

Frente à necessidade imperativa de mudança, tendo em vista o panorama global de desenvolvimento e da escassa falta de cuidados com o meio ambiente, faz-se necessário um despertar da consciência dos seres humanos, visando um novo comportamento social e ambiental, vivenciando assim os valores éticos da Alteridade.

Emmanuel Lévinas (2009) discorre acerca da consciência, quando diz que a humanidade da consciência está na sua responsabilidade para com o Outro. Melo (2003) afirma como essencial o despertar da consciência pelo Outro, e complementa que a humanidade da consciência não está absolutamente nos seus poderes, mas na sua responsabilidade, na passividade, na acolhida, no serviço, na obediência, na obrigação ao respeito de Outrem: é o Outro primeiro.

Uma série de mudanças, do ponto de vista da consciência e da preocupação com o Outro devem se estabelecer no caminho à Sustentabilidade. Berlim (2012) aponta que a miséria mental dos países desenvolvidos não permite, por exemplo, que se diminuam as discrepâncias e a miséria material das sociedades subdesenvolvidas. A autora traz como ponto relevante que o homem deve criar a consciência e despertar para esse grande problema: o subdesenvolvimento mental que cerca os países de primeiro mundo.

Para Pelizzoli (2002), o mundo atual vive uma constante desordem, em que as elites não podem mais permitir que os povos continuem a mercê de seus males e ilusões, abandonados perante os sistemas opressores vigentes.

Outro ponto a ser discutido, é alçado por Manzini (2008) ao questionar como se poderá considerar sustentável uma sociedade onde cada necessidade, mesmo a mais básica e mundana, é satisfeita através de um custoso e complexo sistema de produtos e serviços. Para o autor a qualidade de um determinado contexto, será sempre o resultado proporcional ao cuidado que as pessoas que ali vivem dispensam a ele.

A humanidade vive hoje com a ideia operante e amplamente difundida de bem-estar, nascida com a revolução industrial. Manzini (2008) esclarece que o conceito de bem-estar conduz o homem a um consumo intrinsecamente insustentável dos recursos ambientais, e alerta que essa maneira de pensar e de se comportar deve mudar nos próximos anos, tendo em vista os limites do planeta. O autor aponta que alguns passos em direção à mudança já estão sendo dados, porém o momento e o modo nos quais um efetivo processo de transformação virá à luz é ainda uma questão aberta, sem resposta.

Vezzoli e Manzini (2007) descrevem que:

\begin{abstract}
A transição para a sustentabilidade será um processo de aprendizagem social através da qual progressivamente entre erros e contradições - como sempre acontece no processo de aprendizagem - nós teremos que aprender a viver meIhor consumindo (muito) menos e regenerando a qualidade do ambiente, ou seja, do ecossistema global e dos contextos locais onde vivemos. (VEZZOLI; MANZINI, 2007, p. 34, tradução nossa).
\end{abstract}

Essa afirmação declara a necessidade das sociedades em diminuírem o consumo de recursos ambientais e de regenerar o ambiente físico e global. Novamente aqui, conceitos de caráter sustentável encontram-se com o pensamento filosófico de Emmanuel Lévinas. Consoante Melo (2003), o despertar para a responsabilidade, enquanto escuta atento e obediente ao apelo do Outro (sendo o Outro um indivíduo, a sociedade ou o planeta e seu ecossistema), é o único caminho autêntico, o único fundamento da consciência do homem. Na responsabilidade 
do Eu pelo Outro, está a consciência acordada, marcada pela bondade ética, que reordena a existência do sujeito, convertendo-a de egocêntrica, para a serviço do Outro.

\section{CONCLUSÕES}

O presente artigo teve como intuito o desenvolvimento de uma reflexão acerca do momento atual da sociedade e o seu modo de vida insustentável, estabelecendo um comparativo com a filosofia de Emmanuel Lévinas e principalmente de seus escritos sobre a Ética da Alteridade.

Pensar a Alteridade e a Ética na Sustentabilidade refere-se a possibilitar ao homem uma melhor convivência com o seu semelhante e com a natureza. A humanidade vive em um ambiente que exige e depende do estabelecimento da Ética da Alteridade para se manter saudável e continuar provendo o sustento a todos que necessitam dela para sobreviver.

Os caminhos trilhados pelo homem até então, o impulsionou a explorar seu planeta de forma irracional e insustentável, culminando com o comprometimento de grande parte dos recursos naturais, recursos que o homem utiliza em sua sobrevivência. Esse comportamento visando somente o progresso e a emancipação das sociedades e dos bens materiais levou o homem a perder sua Alteridade, a deixar de ver o Outro, de se colocar em seu lugar, de se comprometer e de respeitar o Outro, conduzindo-o para a violência crescente, para as guerras e disputas, para o desnível econômico e para a deterioração progressiva do ambiente.

Após o panorama traçado, nota-se a necessidade ímpar da humanidade em realizar uma profunda reflexão acerca dos caminhos insustentáveis, do ponto de vista ambiental, trilhados por ela. É necessária uma mudança nos padrões vigentes, sendo prioritária uma ampliação da consciência do homem, para que possa integrar ao seu modo de vida os valores alteritários, em uma comunhão de harmonia e respeito com o seu ambiente, com o seu planeta e com todos aqueles que nele habitam.

\section{REFERÊNCIAS}

BERLIM, L. Moda e sustentabilidade: uma reflexão necessária. São Paulo: Estação das Letras, 2012.

BERNARDES, C. A ética da alteridade em Emmanuel Levinas: uma contribuição atual ao discurso da moral cristã. Revista de Cultura Teológica - v. 20 - n. 78 - Abr/ Jun 2012. P. 83-101

BROWN, Sass. Eco Moda. Modena: Logos, 2010.
COSTA, M. Levinas: uma introdução. Petrópolis: Vozes, 2000.

EDWARDS, B. O guia básico para a sustentabilidade. Barcelona: Gustavo Gili, 2008.

KAZAZIAN, T. Haverá a idade das coisas leves: design e desenvolvimento sustentável. São Paulo: Senac, 2005.

LÉVINAS, E. Entre Nós: ensaios sobre a alteridade. 4 ed. Petrópolis: Vozes, 2009.

MAKIUCHI, M. Alteridade e educação ambiental. Pesquisa em Educação Ambiental, Brasília, v. 06, n. 01, p. 85-99, 2011.

MANZINI, E. Design para a inovação social e sustentabilidade: comunidades criativas, organizações colaborativas e novas redes projetuais. Rio de Janeiro: E-papers, 2008.

MELO, N. A ética da alteridade em Emmanuel Levinas. Porto Alegre. EDIPUCRS, 2003.

PELIZZOLI, Marcelo Luiz. Levinas: a reconstrução da subjetividade. Porto Alegre. EDIPUCRS, 2002.

PINTO, A. Alteridade: categoria fundamental da ética ambiental. Jus Navigandi, Teresina, n. 1494, 4 ago 2007. Disponível em: <http://jus.com.br/artigos/10241> Acesso em: 7 jan 2014.

SCHULTE, N.; ROSA, L. Moda Sustentável. In: SANT'ANNA, Mara Rúbia (Org.). Moda e Produto. São Paulo: Estação das Letras e Cores, 2010.

SIDEKUN, A. Cultura e Alteridade. In: Cultura e Alteridade: questões conceituais. Ijuí, Rio Grande do Sul, 2006.

SOLDERA, L.; MOREIRA, S.; SCAPIN, E.; UBERTI, D.; RODRIGUES, R. A Alteridade Como Fundamento Da Ética Levinasiana. In: ANAIS do II Seminário Nacional de Filosofia e Educação - UFSM, 2006. Disponível em: <http://coral.ufsm.br/gpforma/2senafe/PDF/018e3.pdf> Acesso em: 28/10/2013.

VEZZOLI, C.; MANZINI, E. Design per la sostenibilità ambientale. Bologna: Zanichelli, 2007. 